\title{
Blood Pressure-to-height Ratios Can Identify Hypertension in Bantu Young Adults from Kinshasa in Democratic Republic of Congo
}

\author{
Danny Mafuta-Munganga ${ }^{1}$, Benjamin Lupenzi-Masikini ${ }^{1}$, Pascal Bayauli-Mwasa ${ }^{1}$, \\ Jean Bosco Kasiam-Lasi-On'Kin ${ }^{1}$, Joseph Bidingija-Mabika ${ }^{1}$, Symphorien Ditu-Mpandamadi ${ }^{1}$, \\ Remy Kapongo ${ }^{1}$, Magloire Atantama ${ }^{1}$, Dominique Mupepe-Mayuku ${ }^{1}$, \\ Jean-Marie Kayembe-Ntumba ${ }^{1}$, Blaise Makoso-Nimi ${ }^{1,2,4}$, Benjamin Longo-Mbenza ${ }^{1,2,3}$ \\ ${ }^{1}$ Department of Internal Medicine, University of Kinshasa, Kinshasa, Democratic Republic of the Congo \\ ${ }^{2}$ Department of Public Health, Lomo University of Research, Kinshasa, Democratic Republic of the Congo \\ ${ }^{3}$ Faculty of Health Sciences, Walter Sisulu University, Mthatha, Eastern Cape, South Africa \\ ${ }^{4}$ Department of Internal Medicine, University ofPresident Joseph KASA-VUBU, Boma, Democratic Republic of Congo
}

Email address:

danny.mafuta@gmail.com (D. Mafuta-Munganga), lupenzibenjamin@gmail.com (B. Lupenzi-Masikini), bayaulipascal@gmail.com (P. Bayauli-Mwasa), kasiamonkin@yahoo.fr (J. B. Kasiam-Lasi-On'Kin),

joseph.bidingija@unikin.ac.cd (J. Bidingija-Mabika),kapongoremy@gmail.com (R. Kapongo),dratamagloire80@gmail.com (M. Atantama), docmupepe@gmail.com (D. Mupepe-Mayuku),dr12jmkayembe@yahoo.com (Jean-Marie Kayembe-Ntumba),

docteurmakoso@gmail.com (B. Makoso-Nimi), longombenza@gmail.com (B. Longo-Mbenza)

\section{To cite this article:}

Danny Mafuta-Munganga, Benjamin Lupenzi-Masikini, Pascal Bayauli-Mwasa, Jean Bosco Kasiam-Lasi-On'Kin, Joseph Bidingija-Mabika, Symphorien Ditu-Mpandamadi, Remy Kapongo, Magloire Atantama, Dominique Mupepe-Mayuku, Jean-Marie Kayembe-Ntumba, Blaise Makoso-Nimi, Benjamin Longo-Mbenza. Blood Pressure-to-height Ratios Can Identify Hypertension in Bantu Young Adults from Kinshasa in Democratic Republic of Congo. European Journal of Preventive Medicine. Vol. 9, No. 2, 2021, pp. 46-50. doi: 10.11648/j.ejpm.20210902.13

Received: February 14, 2021; Accepted: February 27, 2021; Published: April 1, 2021

\begin{abstract}
Background: The diagnosis of hypertension in children and adolescents is not always easy. The blood pressure-toheight ratios (BPHR) have been proposed as a screening tool for diagnosing hypertension. Objective: To evaluate the diagnostic value of BPHR for detecting hypertension in young adults. Methods: A cross-sectional study was conducted among 12621 healthy young adults aged of 18-25 years in Kinshasa, from July 2018 to February 2019. Systolic blood pressure-to-height ratio (SBPHR) was calculated as systolic blood pressure (SBP) in $\mathrm{mmHg}$ devised by height in centimeter. Diastolic blood pressure-to-height ratio (DBPHR) was calculated as diastolic blood pressure (DBP) in $\mathrm{mmHg}$ devised by height in centimeter. The receiver operating characteristics (ROC) curve analysis had allowed determining the cut-off points of SBPHR and DBPHR to detect hypertension. Results: The prevalence of hypertension, prehypertension, obesity and overweight were $10.5 \%, 9.2 \%, 3.0 \%$ and $22.4 \%$ respectively. The median values of SBPHR were $0.75(0.69-0.79) \mathrm{mmHg} / \mathrm{cm}$ and $0.77(0.67-0.80) \mathrm{mmHg} / \mathrm{cm}$ respectively in men and in women. The median values of DBPHR were $0.48(0.44-0.53) \mathrm{mmHg} / \mathrm{cm}$ and $0.51(0.49-0.56) \mathrm{mmHg} / \mathrm{cm}$ respectively in men and in women. Optimal cutoff points of SBPHR to identify hypertensionwere $0.81 \mathrm{mmHg} / \mathrm{cm}$ and $0.89 \mathrm{mmHg} / \mathrm{cm}$ respectively in men and in women. The threshold of DBPHR to detect hypertension was $0.54 \mathrm{mmHg} / \mathrm{cm}$ in both men and women. SBPHR and DBPHR had high sensitivity and specificity for identifying hypertension. Conclusion: SBPHR and DBPHR can be used to detect hypertension in Bantu young adults in Kinshasa.
\end{abstract}

Keywords: Blood Pressure-to-height Ratios, Hypertension, Diagnosis, Bantu Young Adults, Kinshasa 


\section{Introduction}

Hypertension is analterable risk factor for cardiovascular events and kidney diseases globally. Elevated blood pressure (BP) is associated with a large global burden of cardiovascular diseases and premature death $[1,2]$. In 2010, estimates suggest that 1.39 billion individuals worldwide had hypertension [3]. Age, high sodium intake, low potassium intake, alcohol consumption, lack of physical activity, overweight, obesity and unhealthy diet are known as risk factors for hypertension [3]. Approximately 7.8million of deaths in 2015 were associated with systolic BP $\geq 140 \mathrm{mmHg}$ [4]. Several studies had established that Blood pressure-toheight ratios (BPHR) may be used as a tool for detecting hypertension and prehypertension in children and adolescents [5-9]. The aim of this study was to confirm whether BPHR can be used as a screening test for diagnosing hypertension in Bantu young adults at Kinshasa.

\section{Methods}

\subsection{Participants}

A cross-sectional survey on the diagnostic of hypertension and associated cardiovascular risk factors among candidates enrolled at Kinshasa University was done. The details of the study design have been described previously [10]. In brief, the study was performed from July 2018 to February 2019. Participants, aged 18 to 25 years, with informed consent were included. For this purpose, both a detailed medical history and a complete physical examination were performed before the study. Participants with a diagnosis of secondary hypertension, acute or chronic illnesses, infections, renal or hepatic diseases or neoplastic or who were under medical treatment were excluded. A total of 12621 participants were analyzed in this study.

\subsection{Measurements}

Anthropometric measurements, including height and weight, were performed when participants were without shoes and in light clothing. Height and weight were measured to the nearest $0.1 \mathrm{~cm}$ and $0.1 \mathrm{~kg}$, respectively. Body mass index (BMI) was defined as weight $(\mathrm{kg})$ divided by height $(\mathrm{m})$ squared. Blood pressure was measured three times with a mercury sphygmomanometer while the participants were seated after $10 \mathrm{~min}$ of rest, and the three measurements were averaged for analysis.

\subsection{Definitions}

Hypertension was defined as systolic blood pressure (SBP) and/or diastolic blood pressure (DBP) above $95^{\text {th }}$ percentile. Prehypertension was defined as BP between the $90^{\text {th }}$ and the $95^{\text {th }}$ percentile.

The following equations for blood pressure-to-height ratio (BPHR) were used:

Systolic blood pressure-to-height ratio $(\mathrm{SBPHR})=\mathrm{SBP}$ $(\mathrm{mmHg}) /$ height $(\mathrm{cm})$

Diastolic blood pressure-to-height ratio $(\mathrm{DBPHR})=\mathrm{DBP}$ $(\mathrm{mmHg}) /$ height $(\mathrm{cm})$.

The nutritional status was defined according to the specific thresholds of BMI in Kinshasa Hinterland [11]:

Table 1. Definition of levels of cardio metabolic risk by BMI in both sex.

\begin{tabular}{lcl}
\hline Nutritional status & Local cut-off points of BMI & Cardio-metabolic risk \\
\hline Denutrition & 15 & Undetermined \\
Normal weight & $15-22.9$ & Reference \\
Overweight & $23-26.9$ & Light \\
Obesity & & \\
Grade I & $27-29.9$ & Moderate \\
Grade II & $30-33.9$ & High \\
Grade III & $\geq 34$ & Very high \\
\hline
\end{tabular}

\subsection{Statistical Analysis}

All analyses were performed using the SPSS 21 statistical software (SPSS for Windows; SPSS, Inc., Chicago, IL, USA) Data were expressed as mean \pm standard deviation or median (range) for continuous variables and number (\%) for categorical variables. The Pearson Chi-squared test was used to compare proportions. The Student's t-test was used to compare the means of two groups with normal distributions. Mann-Whitney U test and Kruskal Wallis U test were applied for skewed distribution. The Pearson coefficient was used to measure the strength of association between two variables.

In order to determine the accuracy of SBPHR and DBPHR as diagnostic tests for elevated blood pressure (elevated BP), we used the receiver operating characteristic curve analyses. The discriminating power of the SBPHR and the DBPHR was expressed as area under the curve (AUC) and 95\% confidence intervals (CI). An AUC value of $\geq 0.90$ was considered an excellent accuracy [12]. The sensitivity and specificity of SBPHR and DBPHR as indicators of hypertension were determined with cutoff values. The Youden index was used to determine optimal cutoff values SBPHR and DBPHR for identification of hypertension (maximum value of (sensitivity + specificity -1$)$ ). The $p$ value $<0.05$ was considered to be statistically significant.

\section{Results}

Data was generated from 7410 men and 5211 women. The mean ages were 20.1 \pm 2.2 years and 19.2 \pm 1.1 years respectively in men and in women. The prevalence of hypertension was $10.5 \%$. The prevalence of Hypertension was higher in men $(13.0 \%$ versus $6.9 \%$ in women, $p<0.001)$. 
In this study, 9.2\% had Prehypertension, 3.0\% were obese, and $22.4 \%$ were overweight. Table 1 presents the clinical characteristics of the study population according to the sex. Men had significantly higher average of age, height, weight,
BMI, SBP than did women $(p<0.001)$. The median value of SBPHR and DBPHR were 0.75 and $0.50 \mathrm{mmHg} / \mathrm{cm}$ respectively in overall group. The levels of DBP, SBPHR and DBPHR were higher in female than in men $(p<0.001)$.

Table 2. Clinical characteristics of the study participants by sex.

\begin{tabular}{|c|c|c|c|c|}
\hline Variables & All $(n=12621)$ & $\operatorname{Men}(n=7410)$ & Women $(n=5211)$ & $p$-value \\
\hline Age, year & $19.7 \pm 1.9$ & $20.1 \pm 2.2$ & $19.2 \pm 1.1$ & $<0.001$ \\
\hline Height, m & $1.68(1.62-1.73)$ & $1.69(1.66-1.76)$ & $1.62(1.60-1.70)$ & $<0.001$ \\
\hline Weight, kg & $58.0 \pm 9.0$ & $61.4 \pm 8.0$ & $53.2 \pm 8.1$ & $<0.001$ \\
\hline BMI, $\mathrm{kg} / \mathrm{m}^{2}$ & $20.8 \pm 3.0$ & $21.1 \pm 2.9$ & $20.3 \pm 3.0$ & $<0.001$ \\
\hline $\mathrm{SBD}, \mathrm{mmHg}$ & $125.3 \pm 10.7$ & $127.1 \pm 9.7$ & $122.9 \pm 11.6$ & $<0.001$ \\
\hline DBP, $\mathrm{mmHg}$ & $81.8 \pm 12.7$ & $81.0 \pm 13.3$ & $83.1 \pm 11.7$ & $<0.001$ \\
\hline $\mathrm{SBPHR}, \mathrm{mmHg} / \mathrm{cm}$ & $0.75(0.69-0.79)$ & $0.75(0.69-0.79)$ & $0.77(0.67-0.80)$ & $<0.001$ \\
\hline DBPHR, mmHg/cm & $0.50(0.45-0.54)$ & $0.48(0.44-0.53)$ & $0.51(0.49-0.56)$ & $<0.001$ \\
\hline HTA & $1322(10.5)$ & $960(13.0)$ & $362(6.9)$ & $<0.001$ \\
\hline PreHTA & $1164(9.2)$ & $371(5.0)$ & $793(15.2)$ & $<0.001$ \\
\hline Overweight & $2821(22.4)$ & $2061(16.3)$ & $760(6.0)$ & $<0.001$ \\
\hline Obesity & $383(3.0)$ & $174(1.4)$ & $209(1.7)$ & $<0.001$ \\
\hline
\end{tabular}

Values are expressed as medians (IQR) and means \pm SD. $B M I$ body mass index, $S B P$ systolic blood pressure, $D B P$ diastolic blood pressure, $S B P H R$ systolic blood pressure-to-height ratio, DBPHR diastolic blood pressure-to-height ratio, HTA hypertension, PreHTA prehypertension

Table 3 present the distribution by age group of height, BP and BPHR in men. The height and SBP were significantly elevated respectively in 19 and 20 years old group. The DBP, SBPHR and DBPHR were significantly high among participants aged of 21 years old.

Table 3. Distribution by age group of Height, BP and BPHRin men.

\begin{tabular}{lllllll}
\hline Age (year) & $\mathbf{N}$ & Height $(\mathbf{m})$ & SBP $(\mathbf{m m H g})$ & DBP $(\mathbf{m m H g})$ & SBPHR $(\mathbf{m m H g} / \mathbf{c m})$ \\
\hline 18 & 1613 & $1.72(1.68-1.75)$ & $125.9 \pm 10.0$ & $76.7 \pm 12.0$ & $0.75(0.69-0.76)$ \\
19 & 1639 & $1.78(1.67-1.82)$ & $127.4 \pm 7.8$ & $81.3 \pm 10.0$ & $0.73(0.67-0.77)$ \\
20 & 2068 & $1.69(1.66-1.79)$ & $129.7 \pm 10.0$ & $81.8 \pm 14.7$ & $0.75(0.73-0.81)$ \\
21 & 713 & $1.69(1.68-1.70)$ & $126.6 \pm 10.3$ & $84.9 \pm 12.4$ & $0.78(0.69-0.80)$ & $0.47(0.40-0.50)$ \\
$>21$ & 1377 & $1.65(1.60-1.70)$ & $124.3 \pm 9.8$ & $82.3 \pm 14.9$ & $0.75(0.72-0.82)$ \\
$p$ & & $<0.001$ & $<0.001$ & $<0.001$ & $<0.44-0.53)$ & $0.52(0.48-0.55)$ \\
\hline
\end{tabular}

Table 4 present the distribution by age group of height, BP and BPHR in women. The height was significantly elevated in $>21$ years old group. The SBP, DBP, SBPHR and DBPHR were significantly high among participants in 20 years old group.

Table 4. Distribution by age of Height, BP and BPHRin women.

\begin{tabular}{|c|c|c|c|c|c|c|}
\hline Age (year) & $\mathbf{N}$ & Height (m) & SBP (mmHg) & DBP (mmHg) & SBPHR (mmHg/cm) & DBPHR (mmHg/cm) \\
\hline 18 & 1616 & $1.63(1.60-1.72)$ & $125.1 \pm 15.7$ & $83.5 \pm 13.5$ & $0.76(0.72-0.80)$ & $0.51(0.45-0.56)$ \\
\hline 19 & 2068 & $1.62(1.60-1.65)$ & $121.5 \pm 9.2$ & $81.4 \pm 9.3$ & $0.77(0.69-0.78)$ & $0.50(0.49-0.54)$ \\
\hline 20 & 824 & $1.60(1.49-1.65)$ & $126.6 \pm 7.5$ & $87.9 \pm 13.7$ & $0.80(0.78-0.86)$ & $0.59(0.55-0.62)$ \\
\hline 21 & 466 & $1.61(1.49-1.62)$ & $120.4 \pm 5.6$ & $81.4 \pm 9.4$ & $0.77(0.76-0.77)$ & $0.53(0.49-0.58)$ \\
\hline$>21$ & 237 & $1.70(1.70-1.70)$ & $112.2 \pm 6.7$ & $81.4 \pm 7.8$ & $0.65(0.65-0.65)$ & $0.49(0.49-0.49)$ \\
\hline
\end{tabular}

The correlation between SBPHR and age $(r=0.054$, $p<0.001$ for men and $r=0.070, p<0.001$ for women) was much weak than the correlation between SBP and age $(r=$ $0.110, p<0.001$ for men and $r=0.152, p<0.001$ for women). The correlation between DBPHR and age $(r=0.192, p<0.001$ for men and $r=0.052, p<0.001$ for women) was much strong than the correlation between DBP and age $(r=0.120, p<0.001$ for men and $r=0.005, p=0.724$ for women). SBPHR showed a strong positive correlation with SBP in men $(r=0.842$, $p<0.001)$ and women $(r=0.892, p<0.001)$. In men, SBPHR and DBPHR were positively correlated with BMI. DBPHR was positively correlated with DBP in men $(r=0.966$, $p<0.001)$ and women $(r=0.946, p<0.001)$, as reported in table 5. 
Table 5. Pearson correlation between SBPHR, DBPHR and other parametersby sex.

\begin{tabular}{lllllll}
\hline Men & SBPHR $(\mathbf{m m H g} / \mathbf{c m})$ & DBPHR $(\mathbf{m m H g} / \mathbf{c m})$ & \multirow{2}{*}{ BMI $\left(\mathbf{K g} / \mathbf{m}^{2}\right)$} & Age (year) & SBP $(\mathbf{m m H g})$ & DBP $(\mathbf{m m H g})$ \\
\hline Women & - & $0.453^{*}$ & $0.384^{*}$ & $0.054^{*}$ & $0.842^{*}$ & $0.359^{*}$ \\
SBPHR (mmHg/cm) & - & - & $0.222^{*}$ & $0.192^{*}$ & $0.284^{*}$ & $0.966^{*}$ \\
DBPHR (mmHg/cm) & 0.505 & 0.004 & - & $0.115^{*}$ & $0.181^{*}$ & $0.129^{*}$ \\
BMI (kg/m $)$ & 0.001 & $0.052^{*}$ & $0.126^{*}$ & - & $-0.110^{*}$ & $0.120^{*}$ \\
Age (year) & $-0.070^{*}$ & $0.414^{*}$ & $-0.131^{*}$ & $-0.152^{*}$ & - & $0.331^{*}$ \\
SBP (mmHg) & $0.892^{*}$ & $0.946^{*}$ & $-0.088^{*}$ & 0.005 & $0.439^{*}$ & - \\
DBP (mmHg) & $0.383^{*}$ & & & & & \\
\hline
\end{tabular}

${ }_{p}^{*}<0.001$

The abilities of SBPHR and DBPHR to accurately define hypertension were assessed by AUC. Table 6shows that the accuracy levels of SBPHR for identifying elevated SBP (as assessed by AUC) were respectively $0.935(0.927-0.942)$ and $0.999(0.998-1.000)$ in men and in women. Whereas the accuracy levels of DBPHR for identifying elevated DBP were respectively $0.976(0.972-0.979)$ and $0.955(0.949-$
0.960) in men and in women. The optimal cutoff points of SBPHR for detecting elevated SBP were respectively $0.81 \mathrm{mmHg} / \mathrm{cm}$ and $0.89 \mathrm{mmHg} / \mathrm{cm}$ in men and in women. The sensitivity and specificity were over $85 \%$. The optimal cutoff point of DBPHR for detecting elevated DBP was 0.54 $\mathrm{mmHg} / \mathrm{cm}$ in both men and women. The sensitivity and specificity were over $80 \%$.

Table 6. Area under the curve, cutoff fvalues, sensitivities, and specificities of SBPHR and DBPHR for diagnosing elevated SBP and DBP by sex.

\begin{tabular}{llllllll}
\hline Gender & $\mathbf{n}$ & BPHR & AUC (95\% CI) & $\boldsymbol{p}$ & Cutoff & Se (\%) & Sp (\%) \\
\hline \multirow{2}{*}{ Men } & \multirow{2}{*}{ (410 } & SBPHR & $0.935(0.927-0.942)$ & $<0.001$ & 0.81 & 90.9 & 88.6 \\
& & DBPHR & $0.976(0.972-0.979)$ & $<0.001$ & 0.54 & 85.1 & 99.1 \\
\multirow{2}{*}{ Women } & \multirow{2}{*}{5211} & SBPHR & $0.999(0.998-1.000)$ & $<0.001$ & 0.89 & 100 & 96.7 \\
& & DBPHR & $0.955(0.949-0.960)$ & $<0.001$ & 0.54 & 96.8 & 80.8 \\
\hline
\end{tabular}

$A U C$ area under the curve, $C I$ confidence interval, $S B P H R$ systolic blood pressure-to-height ratio, DBPHR diastolic blood pressure-to-height ratio

\section{Discussion}

To date, any study has been published from DRC examining of BPHR. Our cross-sectional study, carried out in DRC, aims to evaluate the diagnostic value of BPHR for detecting hypertension in the largest cohort from Bantu young population at Kinshasa.

The prevalence of hypertension and prehypertension in this study are respectively $10.5 \%$ and $9.2 \%$. The similar prevalence has been found by previous studies [13-16]. In this study $3.0 \%$ of participants were obese. Bukabau et al reported a low prevalence of $0.9 \%$ [17]. This difference can be explained by the size of sample, the youth age of participants and WHO criteria used to categorize the nutritional status according to the BMI.

Additionally in this study, the median value of SBPHR and DBPHR were $0.75 \mathrm{mmHg} / \mathrm{cm}$ and $0.50 \mathrm{mmHg} / \mathrm{cm}$ respectively in overall group. Our results agree with former studies $[6,7]$. We also provided cutoff points of BPHR to identify hypertension for each sex. In our study, the cutoff points of SBPHR were $0.81 \mathrm{mmHg} / \mathrm{cm}$ and $0.89 \mathrm{mmHg} / \mathrm{cm}$ respectively in men and women. Whereas the cutoff values of DBPHR is $0.54 \mathrm{mmHg} / \mathrm{cm}$ in both men and women. BPHR have high sensitivity and specificity for identifying elevated BP. All AUCs were $>0.9$ indicating good discriminating capacities.

The large sample size and the diverse origins of participants constitute the strength of the present study. However, there is a limitation to the present study.

\section{Conclusion}

BPHR is a simple tool with high sensitivity and specificity to identify hypertension in less than 25 years old persons among Bantu population. To the best of our knowledge, this study is the first in DRC to report the predictive ability of BPHR for hypertension, which can be used as a reliable tool for diagnosing and also screening for high BP in ambulatory care setting in young adults.

\section{Conflict of Interest}

The authors declare that they have no competing interests.

\section{Authors' Contributions}

DMM conceived the study and performed review literature. RK, MA, DMM and BLMcollected data. DMM, JBKLO, BMN and BLM performed statistical analyses. PBM, JBKLO, JBM, JMKN, BLMand SDM participated in the coordination of writing of the study. All authors read and approved the final manuscript.

\section{References}

[1] Zhou D, Xi B, Zhao M. Uncontrolled hypertension increases risk of all-cause and cardiovascular disease mortality in US adults: the NHANES III Linked Mortality Study. Sci Rep. 2018; 8: 9418 https://doi.org/10.1038/s41598-018-27377-2. 
[2] Pugh D, Gallacher PJ, Dhaun N. Management of Hypertension in Chronic Kidney Disease. Drugs. 2019; 79: 365-379https://doi.org/10.1007/s40265-019-1064-1.

[3] Mills KT, Stefanescu A, He J. The global epidemiology of hypertension. Nat Rev Nephrol. 2020; 16: 223-237 https://doi.org/10.1038/s41581-019-0244-2.

[4] Forouzanfar MH et al. Global burden of hypertension and systolic blood pressure of at least110 to $115 \mathrm{~mm} \mathrm{Hg}, 1990$ 2015. JAMA. 2017; 317: 165-182.

[5] Zhang Y, Ma C, Yang L, et al. Performance of modified blood pressure-to-height ratio for identifying hypertension in Chinese and American children. J Hum Hypertens. 2018; 32: 408-414 https://doi.org/10.1038/s41371-018-0056-z.

[6] Yazdi M, Assadi F, Daniali SS, et al. Performance of modified blood pressure-to-height ratio for diagnosis of hypertension in children: The CASPIAN-V study. J ClinHypertens. 2020; 22: 867-875. https://doi.org/10.1111/jch.13860.

[7] Katamba G, Collins Agaba D, Migisha R et al. Using blood pressure height index to define hypertension among secondary school adolescents in southwestern Uganda. J Hum Hypertens. 2020; 34: 76-81. https://doi.org/10.1038/s41371-019-0292-x.

[8] Mourato FA, Mourato MF, Mattos SDS, de Lima Filho JL, de Araújo Gueiros Lira GV, Nadruz W Jr. New modifications of the blood pressure-to-height ratio for the diagnosis of high blood pressure in children. J ClinHypertens (Greenwich). 2018 Feb; 20 (2): 413-415. doi: 10.1111/jch.13178.

[9] Nilgün Çöl, Arda Kilinc, Beltinge Demircioğlu-Kılıç, Neriman Aydin, Mehmet Keskin \& Ayse Balat. Predictive value of the "Blood Pressure To Height Ratio" in diagnosis of prehypertension and hypertension during childhood in Southeastern Turkey. Clinical and Experimental Hypertension. 2019; 41: 1, 14-19, DOI: 10.1080/10641963.2018.1433198.

[10] Mupepe MD, Kayembe NJM, Nkodila NA, Lupenzi MB, Samafundu MY, Kintoki VE. Hypertension and associated cardiovascular risk factors among candidates enrolled at
Kinshasa University for the academic year 2018-2019. Ann. Afr. Med., vol. 13, n 2, Mars 2020, e3575-83.

[11] KasiamLasi On'Kin JB, Longo-Mbenza B, Nge Okwe A, Kangola Kabangu N. Survey of abdominal obesities in an adult urban population of Kinshasa, Democratic Republic of Congo. cardiovasc $j$ afr 2007; 18: 300-307.

[12] Zou KH, O'Malley AJ, Mauri L. Receiver-operating characteristic analysis for evaluating diagnostic tests and predictive models. Circulation 2007; 115: 654-657.

[13] KatchungaPB, Mirindi $\mathrm{P}$, Baleke A, Ntaburhe $\mathrm{T}$, Twagirumukiza $\mathrm{M}$, et al. The trend in blood pressure and hypertension prevalence in the general population of South Kivu between 2012 and 2016: Results from two representative cross-sectional surveys-The Bukavu observational study. $\begin{array}{lllll}P L O S & \text { ONE. 2019; } 14 & \text { (8): } 0219377 .\end{array}$ https://doi.org/10.1371/journal.pone.0219377.

[14] Kianu PB, Mpembele ME, Kintoki VE, Makulo RJR, Kiazayawoko ZF, Manyebwa KJDD et al. Rates of Hypertension Prevalence, Awareness, Treatment, and Control in a Congolese South West Port City. The Influence of Gender According to Age Groups. Global Journal of Medical Research 2015; 15 (1): 1-8.

[15] Mukeba-Tshialala D, Nachega JB, Mutombo-Tshingwali M et al. Obésité, hypertension artérielle, hypercholestérolémie et diabète non traités chez les adultes infectés oupas par le VIH à Mbuji-Mayi (République démocratiquedu Congo). Bull. Soc. Pathol. Exot. 2017; 110: 301-309. https://doi.org/10.1007/s13149-017-0561-2.

[16] Sumaili EK, Krzesinki JM, Cohen EP, Nseka NM. Epidemiology of chronic kidney disease in the Democratic Republic of Congo: review of cross sectional studies from Kinshasa, the capital. NephrolTher2010; 6 (4): 232-239.

[17] Bukabau BJ, Makulo RJR, Pakasa MN, Cohen PE, Lepira BL, Patrick K Kayembe KP et al. Chronic kidney disease among high school students of Kinshasa. BMC Nephrology 2012 13: 24. doi: 10.1186/1471-2369-13-24. 